\title{
Ultrasound-assisted pullulan/montmorillonite bionanocomposite coating with high oxygen barrier properties
}

\begin{tabular}{|r|l|}
\hline Journal: & Langmuir \\
\hline Manuscript ID: & Ia-2012-01781n.R1 \\
\hline Manuscript Type: & Article \\
\hline Date Submitted by the Author: & n/a \\
\hline Complete List of Authors: & $\begin{array}{l}\text { Introzzi, Laura; University of Milan, DeFENS, Food Environmental and } \\
\text { Nutritional Sciences } \\
\text { Blomfeldt, Thomas; KTH, Royal Institute of Technology, Fiber and Polymer } \\
\text { Technology } \\
\text { Trabattoni, Silvia; University of Milan Bicocca, Scienza dei Materiali } \\
\text { Tavazzi, Silvia; University of Milan Bicocca, Scienza dei Materiali } \\
\text { Santo, Nadia; University of Milan, dInterdepartmental Center of Advanced } \\
\text { Microscopy } \\
\text { Schiraldi, Alberto; University of Milan, DeFENS, Food Environmental and } \\
\text { Nutritional Sciences } \\
\text { Piergiovanni, Luciano; University of Milan, DeFENS, Food Environmental } \\
\text { and Nutritional Sciences } \\
\text { Farris, Stefano; University of Milan, DeFENS, Food Environmental and } \\
\text { Nutritional Sciences }\end{array}$ \\
\hline
\end{tabular}


Ultrasound-assisted pullulan/montmorillonite bionanocomposite coating with high oxygen barrier properties

\author{
Laura Introzzi, ${ }^{\mathrm{a}}$ Thomas O. J. Blomfeldt, ${ }^{\mathrm{b}}$ Silvia Trabattoni, ${ }^{\mathrm{c}}$ Silvia Tavazzi, ${ }^{\mathrm{c}}$ Nadia Santo, ${ }^{\mathrm{d}}$ Alberto \\ Schiraldi, ${ }^{a}$ Luciano Piergiovanni, ${ }^{a}$ Stefano Farris ${ }^{{ }^{*}}$ \\ ${ }^{a}$ DeFENS, Department of Food, Environmental and Nutritional Sciences-Packaging Division, \\ University of Milan, Via Celoria 2 - 20133 Milan, Italy \\ ${ }^{b}$ Department of Fiber and Polymer Technology, Royal Institute of Technology, SE-10044, \\ Stockholm, Sweden \\ ${ }^{c}$ Department of Materials Science, University of Milano Bicocca, via Cozzi 53, I-20125 Milan, Italy \\ ${ }^{d}$ Interdepartmental Center of Advanced Microscopy, CIMA, University of Milan \\ Via Celoria 26 - 20133 Milan, Italy
}

\footnotetext{
*Corresponding author. Tel.: +39 0250316654; Fax: +39 0250316672

Email address: stefano.farris@unimi.it (S. Farris) 


\begin{abstract}
In this paper, the preparation and characterization of oxygen barrier pullulan sodium montmorillonite $\left(\mathrm{Na}^{+}-\mathrm{MMT}\right)$ nanocomposite coatings is presented for the first time. Full exfoliation of the platelets during the preparation of the coating water dispersions was mediated by ultrasonic treatment, which turned out to be a pivotal factor in the oxygen barrier performance of the final material even at high relative humidity $(\mathrm{RH})$ conditions (oxygen permeability coefficients $\sim 1.43 \pm$

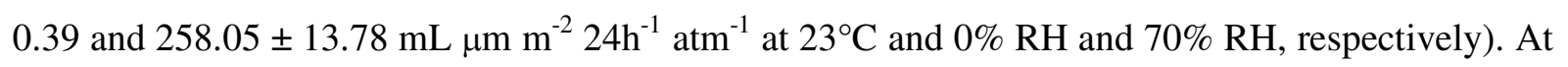
the micro- and nano-scale, the reasons are discussed. The final morphology of the coatings revealed that clay lamellae were stacked on top of one another, probably due to the forced confinement of the platelets within the coating thickness after solvent evaporation. This was also confirmed by modeling the experimental oxygen permeability data with the well-known Nielsen and Cussler permeation theoretical models, which suggested a reasonable aspect ratio $(\alpha)$ of $\sim 100$. Electron microscopy analyses also disclosed a peculiar cell-like arrangement of the platelets. The stacking of the clay lamellae and the cell-like arrangement create the excellent oxygen barrier properties. Finally, we demonstrated that the slight haze increase in the bionanocomposite coating materials arising from the addition of the clays depends on the clay concentration, but not so much on the sonication time, due to the balance of opposite effects after sonication (an increase in the number of scattering centers but a reduction in their size).
\end{abstract}

KEYWORDS: bionanocomposite; coating; modeling; oxygen permeability; pullulan 


\section{Introduction}

Recent advances in nanotechnology include the use of nano-sized particles of both inorganic and organic origin for the improvement of specific properties of the polymer matrix, such as mechanical, thermal, and barrier properties. ${ }^{1}$ Inorganic clays (e.g., montmorillonite, MMT), in particular, have been used extensively to effectively depress the permeation of oxygen molecules across the material thickness..$^{2-4}$ Toward this goal, many different solutions have been proposed; so far, all of them have fallen under the general "nanocomposites" heading. ${ }^{5-9}$

As indicated in previous works, however, the disaggregation and dispersion of the platy layers forming the original macro-particles (tactoids) are the key factors in dictating the full exploitation of the potential involved in the layered clays even at very low loadings $(<5$ weight percent, wt.\%). ${ }^{10,11}$ Only complete exfoliation of the platelets in the polymer matrix would enable the nano-sized clays to expose their high surface area to the polymer. Under this condition, the barrier properties of the polymer finally will be affected by the nano-sized filler in two specific ways: i) a more tortuous path for the diffusion of the permeant and ii) local changes in the polymer matrix properties (e.g., molecular mobility) at the interfacial (polymer-nanoparticle) regions. ${ }^{12}$

For a proper dispersion of the clay platelets in the polymer matrix, various approaches can be used, all of them deriving from two main physical processes: high shear forces and sonication. Sonication is increasingly used in the top-down generation of nano-particles. This is achieved through the deagglomeration and the reduction of micro-sized particles by means of sound waves (more frequently, ultrasound waves) as a result of the mechanical effects of the phenomenon called cavitation, which refers to the formation, growth, and implosive collapse of bubbles in a liquid. ${ }^{13}$ After bubbles collapse, a number of major local events prompt the deagglomeration of micro-sized particles dispersed in the medium: heating ( $5000 \mathrm{~K})$, high pressure $(\sim 1000 \mathrm{~atm})$, huge heatingcooling rates $\left(>10^{9} \mathrm{~K} \mathrm{~s}^{-1}\right)$, and abrupt liquid jet streams $\left(\sim 400 \mathrm{~km} \mathrm{~h}^{-1}\right){ }^{14}$ All of these phenomena 
overcome the attraction forces (electrostatic, van der Waals) holding together the platelets stacked on top of one another to form the aforementioned tactoids.

The same principles first adopted to develop nanocomposites based on oil-derived polymer/inorganic clay systems have more recently been extended to polymers of natural origin (e.g., polysaccharides, proteins, lipids), especially in an attempt to overcome peculiar shortcomings such as water sensitivity and mechanical failures. This opportunity, combined with the increasing attention to more sustainable solutions, has boosted the development of a new subclass of nanocomposite materials, generally called bionanocomposites. To date, many examples of bionanocomposites have been reported in the literature, mostly envisaging the incorporation of the inorganic phase directly into the bulky biopolymer. ${ }^{15-23}$ Conversely, the development of bionanocomposite coatings (i.e., thin layers of a biopolymer matrix loaded with a nanoparticle filler) to improve the oxygen barrier properties of a plastic substrate is rarely encountered. To the best of our knowledge, only two papers have been published so far dealing with bionanocomposite coatings from chitosan and nanoclays laid on poly-lactic acid (PLA) ${ }^{4}$ and low-density polyethylene $(\mathrm{LDPE})^{24}$ films.

In this work, we investigated the potential of a novel bionanocomposite coating based on a natural montmorillonite $\left(\mathrm{Na}^{+}-\mathrm{MMT}\right)$ and pullulan, an exopolysaccharide of microbial origin that has proven to be a valid candidate for replacing synthetic polymers in oxygen barrier coatings ${ }^{25}$ and obtaining high wettable surfaces. ${ }^{26}$ In particular, the oxygen barrier properties of the pullulan/ $\mathrm{Na}^{+}-$ MMT clay composite coatings were investigated in light of the sonication process, i.e., according to different sonication time/clay concentration setups. Moreover, the experimental oxygen permeation characteristics were compared with predictions by various theories available in the literature. The morphological characterization of the bionanocomposite coatings is also reported. 


\section{Experimental Section}

\section{Preparation of coated films}

Pullulan (PF-20 grade, Mn 200 kDa) (Hayashibara Biochemical Laboratories Inc., Okayama, Japan) and a natural montmorillonite, Closite ${ }^{\circledR} \mathrm{Na}^{+}$(Southern Clay Products Inc., Rockwood Additives, Gonzales, TX), were used for the preparation of the bionanocomposite coatings according to the solvent intercalation process. ${ }^{27}$ A fixed amount of pullulan (4 wt.\%, wet basis) was dissolved in distilled water at $25^{\circ} \mathrm{C}$ for 1 hour under gentle stirring (500 rpm). In parallel, different amounts of clay powder were dispersed in distilled water $(18.3 \mathrm{M} \Omega \cdot \mathrm{cm})$ under vigorous stirring (1000 rpm) for 15 minutes. More specifically, the quantity of $\mathrm{Na}^{+}-\mathrm{MMT}$ in water was varied between 0.2 wt. $\%$ and 3.0 wt.\% (wet basis).

Afterward, $50 \mathrm{~mL}$ of the resulting $\mathrm{Na}^{+}-\mathrm{MMT}$ dispersion were ultrasonicated by means of an UP400S (power $_{\max }=400 \mathrm{~W}$; frequency $=24 \mathrm{kHz}$ ) ultrasonic device (Hielscher, Teltow, Germany) equipped with a cylindrical titanium sonotrode (mod. H14, tip $\varnothing 14 \mathrm{~mm}$, amplitude $\max =125 \mu \mathrm{m}$; surface intensity $=105 \mathrm{~W} \mathrm{~cm}^{-2}$ ) under the following conditions: 0.5 cycles and $50 \%$ amplitude. A schematic ultrasonic setup is shown in Figure S1. The duration of the ultrasonic treatment varied in accordance with the experimental design (see Table 1, fourth column).

The organic pullulan solution and the inorganic dispersion were then mixed together under gentle stirring $(500 \mathrm{rpm})$ for an additional 90 minutes. After mixing, the concentrations of the two components corresponded to an inorganic/organic (I/O) ratio ranging from 0.05 to 0.75 (see Table 1, third column). An aliquot of the bionanocomposite water dispersions was then placed on the corona-treated side of rectangular $\left(24 \times 18 \mathrm{~cm}^{2}\right)$ polyethylene terephthalate $(\mathrm{PET})$ films $(12.0 \pm 0.5$ $\mu \mathrm{m}$ thick) provided by Toray (Saehan, Kyungbuk, South Korea). The deposition of the coating was performed using an automatic film applicator (ref 1137, Sheen Instruments, Kingston, UK) at a constant speed of $2.5 \mathrm{~mm} \mathrm{~s}^{-1}$, according to ASTM D823-07 - Practice C. Differences in solid content between the formulations were reset by means of two sequential depositions and using steel 
horizontal rods with different engraved patterns, which yielded final coatings of comparable nominal thickness of $1 \mu \mathrm{m}$ after water evaporation, according to the combinations reported in Figure S1. This coating thickness value has also been confirmed by scanning electron microscopy analysis (see below). Water evaporation was performed using a constant and perpendicular flux of mild air $\left(25.0 \pm 0.3^{\circ} \mathrm{C}\right.$ for 2 minutes $)$ at a distance of $40 \mathrm{~cm}$ from the applicator.

Coated films were then stored under controlled conditions $\left(23.0 \pm 0.5^{\circ} \mathrm{C}, 40.0 \pm 2.0 \% \mathrm{RH}\right)$ for 24 hours. Finally, they were kept in a sealed anhydrous desiccator for at least two weeks before analysis.

\section{Particle size analysis}

The size distribution in water dispersion of the $\mathrm{Na}^{+}$-MMT clays before and after ultrasonic treatment was assessed using an IKO-Sizer CC-1 nanoparticle analyzer (IKO Science, Tallin, Estonia). This instrument, a photon counter mounted on an avalanche photodiode (APD), measures the particle size based on the photon correlation spectroscopy (PCS) technique. More specifically, the instrument determines the velocity distribution of particle movement by measuring the dynamic fluctuations of the intensity of light $(635 \mathrm{~nm})$ scattered at $90^{\circ}$.

The prepared clay dispersions were diluted to a droplet concentration of approximately 0.006 wt.\% before analysis. The Photocor-FC correlator software was used for the data analysis. The particle size measurements are reported as the average and standard deviation of measurements made on two freshly prepared samples, with three readings made per sample.

\section{Electron microscopy observations}

The morphology and microstructure of nanocomposites, especially with reference to the inorganic phase distribution within the pullulan polymer matrix, play a crucial role in determining the ultimate transport properties of the final materials. ${ }^{28}$ Moreover, the morphology and microstructure 
may also affect the final optical properties of the coated PET films owing to both the extent of the dispersion and the uniformity of the distribution of the platelets.

Transmission electron microscopy (TEM) images were captured to visualize the extent of deagglomeration and dispersion of the $\mathrm{Na}^{+}$-MMT clays in both distilled water and pullulan matrix. To this purpose, $5 \mu \mathrm{L}$ of a 3.0 wt. $\%$ water dispersion were deposited onto a Formvar-coated $\mathrm{Cu}$ grid (400 mesh). Observations were made after 24 hours (i.e., the time required to allow solvent evaporation) using an LEO $912 \mathrm{AB}$ energy-filtering transmission electron microscope (EFTEM) (Carl Zeiss, Oberkochen, Germany) operating at $80 \mathrm{kV}$. Digital images were recorded with a ProScan 1K Slow-Scan CCD camera (Proscan, Scheuring, Germany).

Field-emission scanning electron microscopy (FE-SEM) micrographs were obtained to acquire more detailed information on the morphology and global organization of both pure pullulan and clay-loaded pullulan coatings as well as to determine the thickness of the final nanocomposite coatings. Both cross-sections and surfaces of the samples were examined using a Hitachi S-4800 FE-SEM (Schaumburg, IL, USA). Surface test specimens were mounted with carbon tape on stubs. Cross-sectioned samples were cut into thin pieces with a scalpel and mounted on a Hitachi thin specimen split mount holder, M4 (prod. No 15335-4). Before insertion into the microscope, the samples were sputter-coated with gold to a thickness of approximately $10 \mathrm{~nm}$ (to avoid charging the samples) using an Agar High Resolution Sputter Coater (model 208RH) equipped with a gold target/Agar thickness monitor controller.

\author{
Atomic force microscopy \\ The surface morphology of pure pullulan coatings and pullulan nanocomposite coatings was \\ analyzed using an atomic force microscope (AFM) Nanoscope V MultiMode (Veeco) in tapping \\ mode. Measurements were carried out in air using a silicon tip (resonance frequency $287-346 \mathrm{kHz}$, \\ spring constant $20-80 \mathrm{~N} / \mathrm{m}$ ). The images were recorded with a resolution of $512 \times 512$ pixels and


corrected using a second-order polynomial background filter. The root mean square roughness $S$ was also evaluated for each sample as the standard deviation of the topography over the $10 \times 10$ $\mu \mathrm{m}^{2}$ scanning area $(M \times N$ pixels $)$ :

$$
S=\sqrt{\frac{1}{M N} \sum_{i=i}^{M} \sum_{j=1}^{N}\left|z\left(x_{i}, y_{j}\right)-\bar{z}\right|^{2}}
$$

where $\bar{z}$ is the mean value of the topography $z(x, y)$.

\section{Oxygen permeability $\left(\mathrm{P}^{\prime} \mathrm{O}_{2}\right)$ measurements}

The oxygen barrier properties of both uncoated and coated PET films were assessed on a $50 \mathrm{~cm}^{2}$ surface sample using a MultiPerm permeability analyzer (ExtraSolution ${ }^{\circledR}$ Srl, Capannori, Italy) equipped with an electrochemical sensor. Oxygen transmission rate $\left(\mathrm{O}_{2} T R\right)$ data were determined according to the standard method of ASTM F2622-08, with a carrier flow $\left(\mathrm{N}_{2}\right)$ of $10 \mathrm{~mL} \mathrm{~min}^{-1}$ at $23^{\circ} \mathrm{C}, 70 \%$ relative humidity $(\mathrm{RH})$ and at one atmosphere pressure difference on the two sides of the specimen. Analyses were carried out with the coated side of each sample facing the upper semichamber where the humid test gas (oxygen) was fluxed. Each $O_{2} T R$ value was from three replicates. Final $\mathrm{P}^{\prime} \mathrm{O}_{2}$ coefficients were calculated according to the following equation: ${ }^{4}$

$$
P^{\prime} \mathrm{O}_{2}=\mathrm{PO}_{2} \times t=\frac{O_{2} T R}{\Delta p} \times t
$$

In equation $2, P^{\prime} O_{2}$ is the oxygen permeability coefficient $\left(\mathrm{mL} \mu \mathrm{m} \mathrm{m} \mathrm{m}^{-2} 24 \mathrm{~h}^{-1} \mathrm{~atm}^{-1}\right), \mathrm{PO}_{2}$, is the permeance (defined as the ratio of the $\mathrm{O}_{2} T R$ to the difference between the partial pressure of the gas on the two sides of the film, $\Delta p$ ), and $t$ is the total thickness of the material (substrate plus coating).

Haze

Haze is defined as the percentage of transmitted light deviating by more than an angle of $2.5^{\circ}$ from the direction of the incident beam. Quantification of haze is important for all those materials where loss of transparency is detrimental to their function, such as applications relying on maximizing 
solar flux (e.g., greenhouse windows and solar energy arrays). In other circumstances, haze represents an aesthetic attribute that can dictate the consumers' choice, such as in architectural applications (e.g., skylights) and food packaging, where haze is responsible for the reduction in the contrast between objects viewed through the material (e.g., the coated plastic film). In general, haze $\leq 3 \%$ is deemed to be acceptable for most applications as it preserves the original "see through" function of the material.

Haze was measured within the wavelength range 780-380 nm, in accordance with ASTM D 1003-00 using a UV-Vis high-performance spectrophotometer (Lambda 650, PerkinElmer, Waltham, MA, USA) coupled with a $150 \mathrm{~mm}$ integrating sphere, which allows the trapping of the diffuse transmitted light. Three replicates were made for each uncoated and coated film sample.

\section{Experimental design}

In this work, the use of the inorganic filler was aimed primarily at increasing the oxygen barrier properties of the biopolymer matrix laid on the plastic substrate. However, as the inclusion of an inorganic phase can jeopardize the transparency of the final material (e.g., increasing the "hazy" appearance), the addition of the montmorillonite clay was also investigated in light of the influence on the haze properties of the final bionanocomposite coatings/PET films. A chemometric approach based on the Design of Experiment (DoE) technique was thus used to map the simultaneous evolution of the two dependent variables $\left(\mathrm{Y}_{1}=\right.$ oxygen permeability coefficient, $P^{\prime} \mathrm{O}_{2} ; \mathrm{Y}_{2}=$ haze $)$ by varying two independent variables $\left(\mathrm{X}_{1}=\right.$ inorganic/organic ratio $(\mathrm{I} / \mathrm{O}) ; \mathrm{X}_{2}=$ ultrasonication time $)$ within the experimental region defined by a minimum (coded as -1$)$ and a maximum (coded as +1$)$ value (see Table 1). The selection of a Central Composite Face (CCF) design supported by a quadratic polynomial equation allowed the development of a semi-empirical model of the general formula:

$$
Y=b_{0}+b_{1} X_{1}+b_{2} X_{2}+b_{12} X_{1} X_{2}+b_{11} X_{1}^{2}+b_{22} X_{2}^{2}+\varepsilon
$$


where $\mathrm{Y}$ represents the two responses $\left(P^{\prime} O_{2}\right.$ and haze); $X_{1}$ and $X_{2}$ are the codified values of the two factors (inorganic/organic ratio and ultrasonication time); $b_{0}$ is the response value when all factors are set at the medium level (center point); $b_{1}$ and $b_{2}$ are linear regression coefficients; $b_{12}$ is the interaction regression coefficient; $b_{11}$ and $b_{22}$ are quadratic regression coefficients; and $\varepsilon$ is the residual response variation not explained by the model.

In turn, this model made it possible to pinpoint the best factor combination according to the optimization criteria set up for each response. The MODDE software package (MODDE 2006, version 8.0; UMETRICS AB, Umea, Sweden) was used throughout the investigation for the evaluation of raw data and regression analysis.

\section{Results and Discussion}

\section{Effect of clay concentration and sonication time on oxygen-barrier and haze properties}

Based on the experimental data, equation 3 has been used to model the dependence of haze and $P^{\prime} \mathrm{O}_{2}$ on $\mathrm{I} / \mathrm{O}$ ratio and sonication time (see Table 1 ). The model has been found to adequately describe the $P^{\prime} \mathrm{O}_{2}$ and haze data, as indicated by the statistical analysis (Tables 2 and 3) and the fact that the values of the coefficients $R^{2}$ (fitting capability) and $K^{2}$ (prediction capability) are very close to unity. The obtained results are reported in Figure 1.

First, we discuss the dependence of haze and $\mathrm{P}^{\prime} \mathrm{O}_{2}$ on the clay concentration-namely, on I/O. The response 3D contour plot reported in Figure 1a shows that haze increased monotonically with I/O due to the higher extent of visible light diffused by the inorganic particles. In general, an increase in the intensity of the scattered light as a function of clay concentration is attributable either to an increase in the size of the scattering centers or to an increase in their number. Indeed, we can reasonably assume that the scattering centers are optically soft particles (with a similar refractive index as the polymeric matrix) and are relatively large in size (their size $a$ is comparable or larger than $\lambda /(2 \pi), \lambda$ being the wavelength of light). For independent, optically soft, and relatively 
large particles, one can study the scattering in the van-de-Hulst-anomalous-diffraction approximation. ${ }^{29}$ Light scattering increases with the number $\mathrm{N}_{s}$ of independent scattering centers and also with their size $a$, which determines the scattering cross section $\sigma_{\mathrm{s}}=\pi a^{2} \mathrm{Q}$. Q is given by:

$$
Q=2-\frac{4 \sin \rho}{\rho}+\frac{4(1-\cos \rho)}{\rho^{2}}
$$

where $\rho=4 \pi(n-1) a / \lambda, n$ being the ratio between the refractive index of the particle and the refractive index of the polymer matrix. In our case, when increasing the clay concentration (I/O), there is first an increase in $\mathrm{N}_{s}$, followed at $\mathrm{I} / \mathrm{O} \sim 0.5$ by a reaggregation of the nanoparticles (an increase in the size of the scattering centers). This claim is deduced from the $P^{\prime} \mathrm{O}_{2}$ data as a function of I/O (Figure 1b). The $P^{\prime} \mathrm{O}_{2}$ decreased when $\mathrm{I} / \mathrm{O}$ was increased to approximately 0.5 . Above this value, any additional increase in the clay concentration did not bring any appreciable improvement. Rather, the highest inorganic/organic ratio $(\mathrm{I} / \mathrm{O}=0.75)$ apparently had a detrimental effect on the barrier properties of the PET-coated films. As already reported, ${ }^{10,30}$ when the clay content was increased beyond a certain limit, the reaggregation of the platelets to again form tactoids consisting of several stacked silicate monolayers may occur, leading to a micro-composite instead of a nanocomposite structure. It is known that this may reduce the oxygen-barrier performance.

Having found that the I/O ratio influences the oxygen-barrier properties, we then studied the effect of the sonication time. Although it had no significant influence on the haze response, sonication time affects the $P^{\prime} O_{2}$ data. The observed $P^{\prime} O_{2}$ variation suggests that time can be optimized. Exceeding this energy input (prolonged sonication time) may promote reagglomeration, which is then followed by fragmentation for even larger times. For example, for a fixed amount of clay (e.g., 1.5 wt. $\%$ wet basis $\equiv \mathrm{I} / \mathrm{O}=0.375$ ), the most effective sonication time was 15 minutes. Longer treatments first yielded an increase in the $P^{\prime} O_{2}$ values (due to reaggregation), which decreased again at the highest sonication time (45 minutes), presumably owing to the fragmentation of both platelets and tactoids. Our interpretation is also supported by the comparison of Figures 2 and 3. Figure 2a shows an image of a tactoid, which is typically found when the sonication time is 
zero. The sonication treatment produced a positive effect at the nanoscale after 15 minutes (Figure 3), providing the best oxygen-barrier performances. For a further increase of time (but the same I/O ratio), the clay platelets are destroyed and fragments or agglomeration of fragments (Figure 2b) are observed. Therefore, not only the clay concentration (I/O) but also reaggregation and fragmentation dramatically affect the final barrier properties of the composite coatings. Reaggregation causes voids and discontinuities within the main polymer matrix (pullulan in this case), which eventually yields free volume increases $;{ }^{30}$ fragmentation leads to a remarkable reduction in the aspect ratio of the inorganic filler. The invariance of haze as a function of the sonication time allows selecting the proper time to improve the oxygen-barrier performances without substantially affecting the optical properties.

Finally, the findings below have an important practical implication as they can lead to a significant reduction in energy consumption in terms of energy output per unit volume, which can be calculated according to the following formula:

$$
E=\frac{I \cdot S}{V} \times t
$$

where $E$ is the unit energy output $\left(\mathrm{Ws} \mathrm{mL}^{-1}\right) ; I$ the surface intensity $\left(\mathrm{W} \mathrm{cm}{ }^{-2}\right) ; S$ the sonotrode surface area $\left(\mathrm{cm}^{2}\right) ; t$ the time of exposure to the ultrasonic treatment (s); and $V$ the sample volume $(\mathrm{mL})$.

According to the experimental setup adopted in this work, an energy unit output of $725 \mathrm{Ws}$ $\mathrm{mL}^{-1}$ was calculated for the 15-minute treatment while an extended ultrasonication time of 45 minutes yielded a unit energy consumption of $2060 \mathrm{Ws} \mathrm{mL}^{-1}$. This would allow the saving of quite a high amount of energy throughout the whole process, which will eventually be reflected in the final throughput costs. 


\section{Modeling the $\mathrm{P}^{\prime} \mathrm{O}_{2}$ data}

The semi-empirical model expressed by equation 3 made it possible to extrapolate the $P^{\prime} O_{2}$ values of the bionanocomposite-coated PET films for any clay loading within the experimental I/O range of $0.05-0.75$. In turn, this allowed the computation of the contribution of the nanocomposite coatings to the total (i.e., substrate plus coating) $P^{\prime} O_{2}$ values, in accordance with the well-known series resistance formula intended for multilayer systems: ${ }^{31}$

$$
\frac{l_{\text {tot }}}{P_{\text {tot }}}=\frac{l_{P E T}}{P_{P E T}}+\frac{l_{\text {coating }}}{P_{\text {coating }}}
$$

where $P$ represents the oxygen permeability coefficient $\left(P^{\prime} O_{2}, \mathrm{~mL} \mu \mathrm{m} \mathrm{m}^{-2} 24 \mathrm{~h}^{-1} \mathrm{~atm}^{-1}\right)$ of the layer; and $l$ stands for its thickness $(\mu \mathrm{m})$. With knowledge of $l_{\mathrm{tot}}, l_{\mathrm{PET}}, l_{\text {coating }}, P_{\mathrm{tot}}$, and $P_{\mathrm{PET}}$, the $P^{\prime} \mathrm{O}_{2}$ coefficient $\left(P_{\text {coating }}\right)$ for the nanocomposite coatings can be calculated from equation 6 . The results are summarized in Table 4. Finally, these values were fitted with both Nielsen's and Cussler's permeation theoretical models, which describe the permeation phenomenon across a two-phase film—for impermeable square platelets dispersed in a continuous polymer matrix: ${ }^{28}$

$$
\begin{aligned}
& P_{0} / P \cdot(1-\phi)=1+(\alpha \phi) / 2 \\
& P_{0} / P \cdot(1-\phi)=1+(\alpha \phi)^{2} / 4 \\
& P_{0} / P \cdot(1-\phi)=1+(\alpha \phi / 3)^{2}
\end{aligned}
$$

where

$P_{0}=$ permeability parameter of the pure biopolymer coating

$P=$ permeability parameter of the bionanocomposite coatings

$\alpha=$ aspect ratio of the platelets (the width divided by the thickness)

$\phi=$ volume fraction of the platelets dispersed in the biopolymer matrix

The difference between the above models lies in the fact that Nielsen's model (eq. 7) assumes that the filler is evenly dispersed within the matrix and the permeation rate of the gas 
across the polymer matrix is influenced only by the tortuosity of the path; Cussler's models, by contrast, also consider the orientation of the inorganic platelets, which can be either oriented (eq. 8a) or randomly dispersed (eq. 8b). Figure 4 displays the experimental $P^{\prime} O_{2}$ data for the pullulan nanocomposite coatings at different filler volume ratios $(\phi)$, along with the $P^{\prime} O_{2}$ data predicted by Nielsen's and Cussler's models for different aspect ratios $(\alpha)$ between 10 and 100.

For both models, the overall trend of the predicted values is in line with the experimental data generated by the software. Nevertheless, for volume ratios above 0.18 , the experimental data deviated from the calculated curve most likely due to the reagglomeration of the platelets, which causes depletion in the barrier performance following an increase in the free volume of the polymer matrix. ${ }^{31}$ Interestingly, up to $\phi=0.073$ the best prediction obtained by Nielsen's model was for an estimated $\alpha=100$, which is actually in line with the expected aspect ratio of approximately 100150 for montmorillonite clays. ${ }^{32,33}$ However, above $\phi=0.073$ the best fitting was obtained for $\alpha=$ 50. This finding suggests that the clay distribution in the polymer matrix as exfoliated platelets is preserved up to an $\mathrm{I} / \mathrm{O} \sim 0.225$ (i.e., clay concentration $\sim 0.9$ wt.\%, wet basis). After this value, increasing the amount of clay leads to a decrease of $\alpha$, presumably due to the platelets partially stacking on top of one another, according to the proposed "self-similar clay aggregation mechanism". ${ }^{34}$ In addition, it is worth noting that the Cussler's model envisaging a random distribution of the platelets (eq. 8a) provided a better fitting compared with the model (eq. 8b), accounting for a more oriented distribution. This result indicates that the platelets apparently assumed a random rather than an oriented distribution.

\section{Characterization of the best pullulan/clay nanocomposite coating}

Arising from the considerations above, through a software-assisted procedure, it was possible to pinpoint the best factor combination (I/O: 0.3925; sonication time: 15 minutes) to achieve the lowest $P^{\prime} \mathrm{O}_{2}$ value while keeping haze within the $3 \%$ threshold. Accordingly, the "software- 
generated" predicted values for the selected response were $P^{\prime} O_{2}: 239.72 \mathrm{~mL} \mu \mathrm{m} \mathrm{m}^{-2} 24 \mathrm{~h}^{-1} \mathrm{~atm}^{-1}$ $\left(23^{\circ} \mathrm{C}\right.$ and $\left.70 \% \mathrm{RH}\right)$; haze: $2.99 \%$. The experimental $\mathrm{P}^{\prime} \mathrm{O}_{2}$ of the PET/pullulan nanocomposite coating according to the optimized formulation was indeed equal to $258.05 \pm 13.78 \mathrm{~mL} \mu \mathrm{m} \mathrm{m}^{-2} 24 \mathrm{~h}^{-}$ ${ }^{1} \mathrm{~atm}^{-1}$ at $70 \% \mathrm{RH}$, in agreement with the predicted value and well below the $P^{\prime} O_{2}$ value of the neat

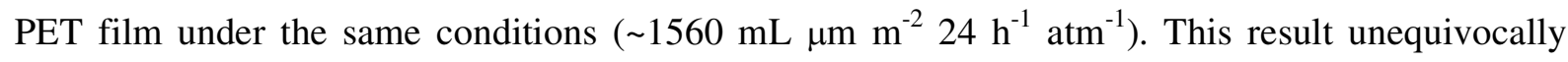
demonstrates that the bionanocomposite coating is effective in decreasing the oxygen permeability of the plastic substrate even at high RH. The same "optimized" bionanocomposite coating provided an impressive $P^{\prime} O_{2}$ value of $1.43 \pm 0.39 \mathrm{~mL} \mu \mathrm{m} \mathrm{m}^{-2} 24 \mathrm{~h}^{-1} \mathrm{~atm}^{-1}\left(\equiv O_{2} T R=0.11 \mathrm{~mL} \mathrm{~m}^{-2} 24 \mathrm{~h}^{-1}\right)$ under dry conditions. These values are decidedly better than those of oxygen barrier polymers such as polyvinyl alcohol (PVOH) and ethylene vinyl alcohol (EVOH), which gradually lose much of their barrier properties starting from $\mathrm{RH}>50 \% .{ }^{35}$ More noticeably, the final PET/bionanocomposite coating structure presented here exhibits an overall performance fully comparable with one of the most widely used oxygen barrier film, the PET/polyvinylidene chloride (PVDC) coating, which has an $\mathrm{O}_{2} \mathrm{TR} \sim 7.5 \mathrm{~mL} \mathrm{~m}^{-2} 24 \mathrm{~h}^{-1}$ at $23^{\circ} \mathrm{C}$ under dry conditions (PET thickness $=12 \mu \mathrm{m}$; coating thickness $=1.4 \mu \mathrm{m}){ }^{36}$

These promising results, the advantages of the bionanocomposite coatings and the efficacy of the ultrasonic treatment on the exfoliation of the $\mathrm{Na}^{+}$-MMT tactoids, motivated us to find other confirmations at the nano- and micro-scale of the occurred modifications. As shown in Figure 5, the particle size distribution of the non-treated clays (red line) included two main groups around two mean values, $3965.0 \pm 462.6 \mathrm{~nm}$ and $178.90 \pm 15.52 \mathrm{~nm}$, accounting for approximately $52.4 \%$ and $47.6 \%$ relative to the total distribution, respectively. After ultrasonic treatment (blue line), a shift toward lower size is clearly observed with a concomitant increase in the percentage of the particles with the smallest size $(\sim 70 \%$ with a mean size of $108.2 \pm 18.9 \mathrm{~nm} ; \sim 23.6 \%$ with a mean size of $2151.0 \pm 894.8 \mathrm{~nm}$ ). Based on these values, a crude estimate of the entity of the possible variation of light scattering after sonication is possible. Indeed, based on equation 4 , it is possible to evaluate 
the scattering cross section $\sigma_{\mathrm{s}}$ for centers of various size $(3965,178,108$, and $2151 \mathrm{~nm}$, respectively). The smallest centers obtained after sonication gave the lowest $\sigma_{\mathrm{s}}$, but their number $\mathrm{N}_{\mathrm{s}}$ strongly increased. The balance between the reduction in average size and the increase in the number of centers is expected to produce a slight net increase in the scattering intensity of about 1.2-1.3 times, as deduced from a simple calculation. This small increase is in reasonable agreement with the approximately constant trend of haze as a function of sonication time shown in Figure 1a. In summary, we observed and rationalized that the optimized coating shows the best performance as an oxygen barrier thanks to its nanostructure, which, however, does not significantly increase the haze.

The information arising from the particle size analysis is in agreement with TEM observations. Figure 3 indicates that the exfoliation of the clay was achieved after ultrasonic treatment, although the platelets were apparently randomly dispersed, with possible generation of a three-dimensional cell-like morphology in the nanometer scale (see the inset of Figure 3). This unusual arrangement might explain the excellent oxygen barrier properties of the nanocomposite coating even at high $\mathrm{RH}$, despite the moderate filler loading. The same information was obtained from the TEM analysis carried out on the optimized bionanocomposite formulation (see Figure S3 of the Supporting Information).

The FE-SEM surface micrographs (Figure 6a) further confirmed the apparently random organization of the clays. Cross-sectional images, besides confirming the average thickness of the bionanocomposite coatings centered at $\sim 1 \mu \mathrm{m}$ (Figure S2), more clearly disclosed a pattern with the platelets oriented along the two dimensions, with a high clay concentration cropping out to the surface (Figures $6 \mathrm{~b}$ and $6 \mathrm{~d}$ ). This is most likely due to the coating deposition technique adopted in this work (the advancement of the wire wound rod would have promoted the horizontal displacement of the clays on the plastic substrate) (Figure 6b). In addition, more detailed inspection revealed that ensuing from the ultrasonic treatment, the exfoliated clays interacted with the 
biopolymer matrix insomuch as every single platelet was "wrapped" by pullulan (Figure 6c). These interactions, presumably mediated by hydrogen bonds between $-\mathrm{OH}$ groups of both pullulan and $\mathrm{Na}^{+}-\mathrm{MMT},{ }^{27}$ had two main consequences: i) The organic/inorganic interface increased dramatically, altering many properties of the polymer matrix, such as the molecular mobility. In turn, this would affect the final oxygen barrier performance of the resulting nanocomposite coating under humid conditions as the relaxation behavior of the strongly hydrophilic biopolymer matrix would have been greatly restricted. ${ }^{34}$ ii) Intercalation of biopolymer chains between pullulan and silicate layers prevented reagglomeration of the clay sheets, pullulan acting as a spacer. This is in agreement with the previously discussed modeling results of the permeability data. Nevertheless, SEM images (Figure 6c) also showed that the well-dispersed and exfoliated clays arranged in a compact structure consisting of two, three, or more platelets stacked on top of one another as if they were forced into a confined space (the coating thickness) upon the drying of the coating. The aforementioned cell-like organization was also detected (Figure 6d).

The $1 \mu \mathrm{m}$ thick coating has been characterized in terms of composition, oxygen barrier, haze properties, and architecture. In terms of architecture, the addition of the inorganic filler dramatically changed the surface morphology of the pullulan coatings. Interestingly, in the absence of the montmorillonite platelets, condensed matter structures referred to as spherulites (Figure 7) were randomly detected on the pullulan coatings' surface. While the feather-like formations (Figure 7a) are likely to be dendritic crystals, typical of synthetic polymers (e.g., PE, PP, and PEO) and biopolymers (e.g., PLA and PHB), the perfectly spherical particles can be viewed as high-order semicrystalline self-assemblies (Figure $7 \mathrm{~b}$ ) already observed in many other natural polymers, such as cellulose,${ }^{37}$ chitin, ${ }^{38}$ chitosan, ${ }^{39}$ and amylose. ${ }^{40}$ In the present study, we hypothesize that the thermodynamic incompatibility between pullulan and PET triggers a phase separation that leads to the aggregation of pullulan, which undergoes a partial crystallization with radial growth around a 
starting nucleus. To the best of our knowledge, this is the first time that the simultaneous presence of these two spherulitic formations in pullulan has been described.

Another morphological change owing to the filler addition is the increase in the roughness of the coating's surface. As highlighted by the AFM analysis on $(10 \times 10) \mu \mathrm{m}^{2}$ areas, the pure pullulan coatings showed highly smooth topographies, with an average roughness of $\sim 1.2 \mathrm{~nm}$ (Figure 8a). The addition of the clays led to a more jagged and wrinkled topography, characterized by a spiky morphology due to the unordered distribution of the platelets within the pullulan matrix. This finally yielded an increased roughness, which, for the optimized formulation $(\mathrm{I} / \mathrm{O} \sim 0.4)$, was $14.7 \mathrm{~nm}$ (Figure 8b). The roughness change between pullulan and $\mathrm{Na}^{+}-\mathrm{MMT} /$ pullulan coatings is another characteristic, which is in reasonable agreement with the ratio $\mathrm{I} / \mathrm{O} \sim 0.4$ between pullulan and $\mathrm{Na}^{+}-\mathrm{MMT}$ in the $1 \mu \mathrm{m}$ thick coating, and with the observed higher concentration of $\mathrm{Na}^{+}-\mathrm{MMT}$ close to the surface.

\section{Conclusions}

Bionanocomposite coatings based on pullulan and $\mathrm{Na}^{+}-\mathrm{MMT}$ were successfully obtained for the first time. The ultrasound-assisted procedure for the exfoliation of the inorganic tactoids resulted in an effective and efficient tool for the final performance of the PET/bionanocomposite material to be achieved as it allowed full exfoliation of the platelets during the preparation of the coating water dispersions. This was reflected in the final oxygen barrier properties of the bionanocomposite coatings, due to both the "tortuosity path" and "organic/inorganic interface" effects. However, the final morphology of the coatings (the clay lamellae stacked on top of one another as well as the peculiar cell-like arrangement of the platelets) might have contributed to the excellent barrier performance even at high $\mathrm{RH}$ conditions. Although the addition of the clays led to an increase in haze, this did not compromise the ultimate optical properties of the final structure. The findings arising from this work reflect convincingly the fact that pullulan nanocomposite coatings are a 
promising alternative to the currently available synthetic oxygen barrier polymer coatings. Among others, food packaging can be considered as a primary field of application for the extension of the shelf life of either perishable food sensitive to oxygen (e.g., fat-containing foods) or foods packaged in a modified atmosphere (MAP) to inhibit microbial spoilage.

Supporting Information Available: Engraved rods combination used throughout the DoE runs. Schematic drawing of the ultrasonication apparatus. FE-SEM cross-sectional images of the bionanocomposite coated PET films. TEM micrograph of the optimized bionanocomposite formulation. This information is available free of charge via the Internet at http://pubs.acs.org/. 


\section{References}

(1) Lam, C.; Lau, K.; Cheung, H.; Ling, H. Effect of Ultrasound Sonication in Nanoclay Clusters of Nanoclay/Epoxy Composites. Mater. Lett. 2005, 59, 1369-1372.

(2) Pojanavaraphan, T.; Magaraphan, R.; Chiou, B. S.; Schiraldi, D. A. Development of Biodegradable Foamlike Materials Based on Casein and Sodium Montmorillonite Clay. Biomacromolecules 2010, 11, 2640-2646.

(3) Liu, A.; Walther, A.; Ikkala, O.; Belova, L.; Berglund, L. A. Clay Nanopaper with Tough Cellulose Nanofiber Matrix for Fire Retardancy and Gas Barrier Functions. Biomacromolecules 2011, 12, 633-641.

(4) Svagan, A. J.; Åkesson, A.; Cárdenas, M.; Bulut, S.; Knudsen, J. C.; Risbo, J.; Plackett D. Transparent Films Based on PLA and Montmorillonite with Tunable Oxygen Barrier Properties. Biomacromolecules 2012, 13, 397-405.

(5) Strawhecker, K. E.; Manias, E. Structure and Properties of Poly(vinyl alcohol)/Na+ Montmorillonite Nanocomposites. Chem. Mat. 2000, 12, 2943-2949.

(6) Cho, J. W.; Paul, D. R. Nylon 6 Nanocomposites by Melt Compounding. Polymer 2001, 42, 1083-1094.

(7) Pereira de Abreu, D. A.; Paseiro Losada, P.; Angulo, I.; Cruz, J. M. Development of New Polyolefin Films with Nanoclays for Application in Food Packaging. Eur. Polym. J. 2007, 43, 2229-2243.

(8) McAdam, C. P.; Hudson N. E.; Liggat, J. J.; Pethrick, R. A. Synthesis and Characterization of Nylon 6/clay Nanocomposites Prepared by Ultrasonication and in Situ Polymerization. J. Appl. Polym. Sci. 2008, 108, 2242-2251.

(9) Manikantan, M. R.; Varadharaju, N. Preparation and Properties of Polypropylene-Based Nanocomposite Films for Food Packaging. Packag. Technol. Sci. 2011, 24, 191-209. 
(10) Bordes, P.; Pollet, E.; Avérous, L. Nano-biocomposites: Biodegradable Polyester/Nanoclay Systems. Prog. Polym. Sci. 2009, 34, 125-155.

(11) Tran N. H.; Wilson, M. A.; Milev, A. S.; Dennis, G. R.; McCutcheon, A. L.; Kannangara, G. S. K.; Lamb, R. N. Structural-chemical Evolution Within Exfoliated Clays. Langmuir 2006, $22,6696-6700$.

(12) Duncan, T. V. Applications of Nanotechnology in Food Packaging and Food Safety: Barrier Materials, Antimicrobials and Sensors. J. Colloid Interface Sci. 2011, 363, 1-24.

(13) Hielscher, T. Ultrasonic Production of Nano-size Dispersions and Emulsions. Proceedings of European Nanosystems Conference ENS ‘05, Paris, 2005.

(14) Suslick, K. S. Kirk-Othmer Encyclopedia of Chemical Technology, 4th Ed., J. Wiley \& Sons: New York, 1998.

(15) Darder, M.; Colilla, M.; Ruiz-Hitzky, E. Biopolymer-clay Nanocomposites Based on Chitosan Intercalated in Montmorillonite. Chem. Mater. 2003, 15, 3774-3780.

(16) Zhou, Q.; Malm, E.; Nilsson, H.; Larsson, P. T.; Iversen, T.; Berglund, L. A.; Bulone, V. Nanostructured Biocomposites Based on Bacterial Cellulosic Nanofibers Compartmentalized by a Soft Hydroxyethylcellulose Matrix Coating. Soft Matter 2009, 5, 4124-4130.

(17) Sehaqui, H.; Zhou, Q.; Berglund, L. A. Nanostructured Biocomposites of High Toughness-A Wood Cellulose Nanofiber Network in Ductile Hydroxyethylcellulose Matrix. Soft Matter 2011, 7, 7342-7350.

(18) Abalde-Cela, S.; Auguié, B.; Fischlechner, M.; Huck, W. T. S.; Alvarez-Puebla, R. A.; LizMarzán, L. M.; Abell, C. Microdroplet Fabrication of Silver-Agarose Nanocomposite Beads for SERS Optical Accumulation. Soft Matter 2011, 7, 1321-1325.

(19) Cabedo, L.; Feijoo, J. L.; Villanueva, M. P.; Lagaron, J. M.; Gimenez, E. Optimization of Biodegradable Nanocomposites Based on a PLA/PCL Blends for Food Packaging Applications. Macromol. Symp. 2006, 233, 191-197. 
(20) Yu, J.; Cui, G.; Wei, M.; Huang, J. Facile Exfoliation of Rectorite Nanoplatelets in Soy Protein Matrix and Reinforced Bionanocomposites Thereof. J. Appl. Polym. Sci. 2007, 104, $3367-3377$.

(21) Zheng, H.; Ai, F.; Chang, P. R.; Huang, J.; Dufresne, A. Structure and Properties of Starch Nanocrystal-Reinforced Soy Protein Plastics. Polym. Composite. 2009, 30, 474-480.

(22) Zhou, J. J.; Wang, S. Y.; Gunasekaran, S. Preparation and Characterization of Whey Protein Film Incorporated with $\mathrm{TiO}_{2}$ Nanoparticles. J. Food Sci. 2009, 74, N50-N56.

(23) Ahmadi, E.; Sareminezhad, S.; Azizi, M. H. The effect of Ultrasound Treatment on Some Properties of Methylcellulose Films. Food Hydrocolloids 2011, 25, 1399-1401.

(24) Vartiainen, J.; Tuominen, M.; Nättinen, K. Bio-hybrid Nanocomposite Coatings from Sonicated Chitosan and Nanoclay. J. Appl. Polym. Sci. 2010, 116, 3638-3647.

(25) Farris, S.; Introzzi, L.; Fuentes-Alventosa, J. M.; Santo, N.; Rocca R.; Piergiovanni, L. Self-Assembled Pullulan-Silica Oxygen Barrier Hybrid Coatings for Food Packaging Applications. J. Agric. Food Chem. 2012, 60, 782-790.

(26) Farris, S.; Introzzi, L.; Biagioni, P.; Holz, T.; Schiraldi, A.; Piergiovanni, L. Wetting of Biopolymer Coatings: Contact Angle Kinetics and Image Analysis Investigation. Langmuir 2011, 27, 7563-7574.

(27) Chivrac, F.; Pollet, E.; Avérous, L. Progress in Nano-Biocomposites Based on Polysaccharides and Nanoclays. Mater. Sci. Eng., R. 2009, 67, 1-17.

(28) Takahashi, S.; Goldberg, H. A.; Feeney, C. A.; Karim, D. P.; Farrell, M.; O’Leary, K.; Paul, D. R. Gas Barrier Properties of Butyl Rubber/Vermiculite Nanocomposite Coatings. Polymer 2006, 47, 3083-3093.

(29) Lui, C.W.; Clarkson, M.; Nicholls, R.W. An Approximation for Spectral Extinction of Atmospheric Aerosols. J. Quant. Spectrosc. Radiat. Transfer 1996, 55, 519-531. 
(30) Wilson, R.; Plivelic, T. S.; Aprem, A. S.; Ranganathaiagh, C.; Kumar S. A.; Thomas, S. Preparation and Characterization of EVA/clay Nanocomposites with Improved Barrier Performance. J. Appl. Polym. Sci. 2011, 123, 3806-3818.

(31) Lee, D. S.; Yam, K. L.; Piergiovanni, L. Food Packaging Science and Technology; CRC Press: Boca Raton, Florida, 2008. p. 88.

(32) Sinha Ray, S.; Okamoto, M. Polymer/layered Silicate Nanocomposites: A Review from Preparation to Processing. Prog. Polym. Sci. 2003, 28, 1539-1541.

(33) Utracki, L. A.; Sepehr, M.; Boccaleri, E. Synthetic, Layered Nanoparticles for Polymeric Nanocomposites (PNCs). Polym. Adv. Technol. 2007, 18, 1-37.

(34) Alexandre, M.; Dubois, P. Polymer-Layered Silicate Nanocomposites: Preparation, Properties and Uses of a New Class of Materials. Mater. Sci. Eng. 2000, 28, 1-63.

(35) Zhang, Z.; Britt, I. J.; Tung, M. A. Permeation of Oxygen and Water Vapor Through EVOH Films as Influenced by Relative Humidity. J. Appl. Polym. Sci. 2001, 82, 1866-1872.

(36) http://www.torayfilms.eu/pdf_upload/tfe_lumirror_22.00_789.pdf

(37) Kobayashi, S.; Hobson, L. J.; Sakamoto, J.; Kimura, S.; Sugiyama, J.; Imai, T.; Itoh, T. Formation and Structure of Artificial Cellulose Spherulites via Enzymatic Polymerization. Biomacromolecules 2000, 1, 168-173.

(38) Murray, S. B.; Neville, A. C. The Role of pH, Temperature and Nucleation in the Formation of Cholesteric Liquid Crystal Spherulites from Chitin and Chitosan. Int. J. Biol. Macromol. 1998, 22, 137-144.

(39) Murray, S. B.; Neville, A. C. The Role of the Electrostatic Coat in the Formation of Cholesteric Liquid Crystal Spherulites from $\alpha$-chitin. Int. J. Biol. Macromol. 1997, 20, 123-130. (40) Ring, S. G.; Miles, M. J.; Morris, V. J.; Turner, R.; Colonna, P. Spherulitic Crystallization of Short Chain Amylase. Int. J. Biol. Macromol. 1987, 9, 158-160. 
Figures
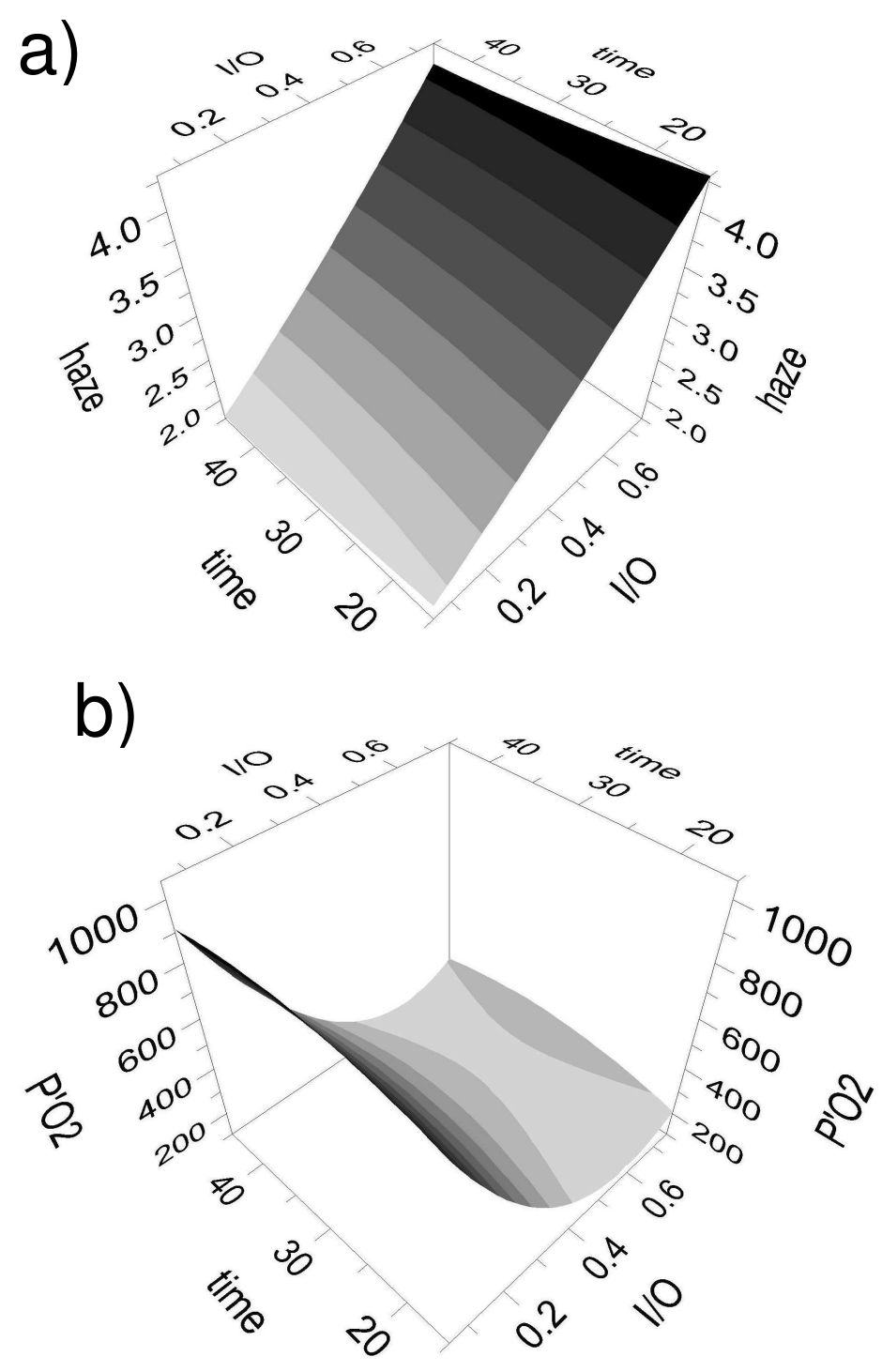

Figure 1. Response surface plots showing the influence of inorganic/organic ratio (I/O) and sonication time (in minutes) on a) haze (\%) and b) oxygen permeability coefficient $\left(\mathrm{P}^{\prime} \mathrm{O}_{2}, \mathrm{~mL} \mu \mathrm{m}\right.$ $\left.\mathrm{m}^{-2} 24 \mathrm{~h}^{-1} \mathrm{~atm}^{-1}\right)$. 

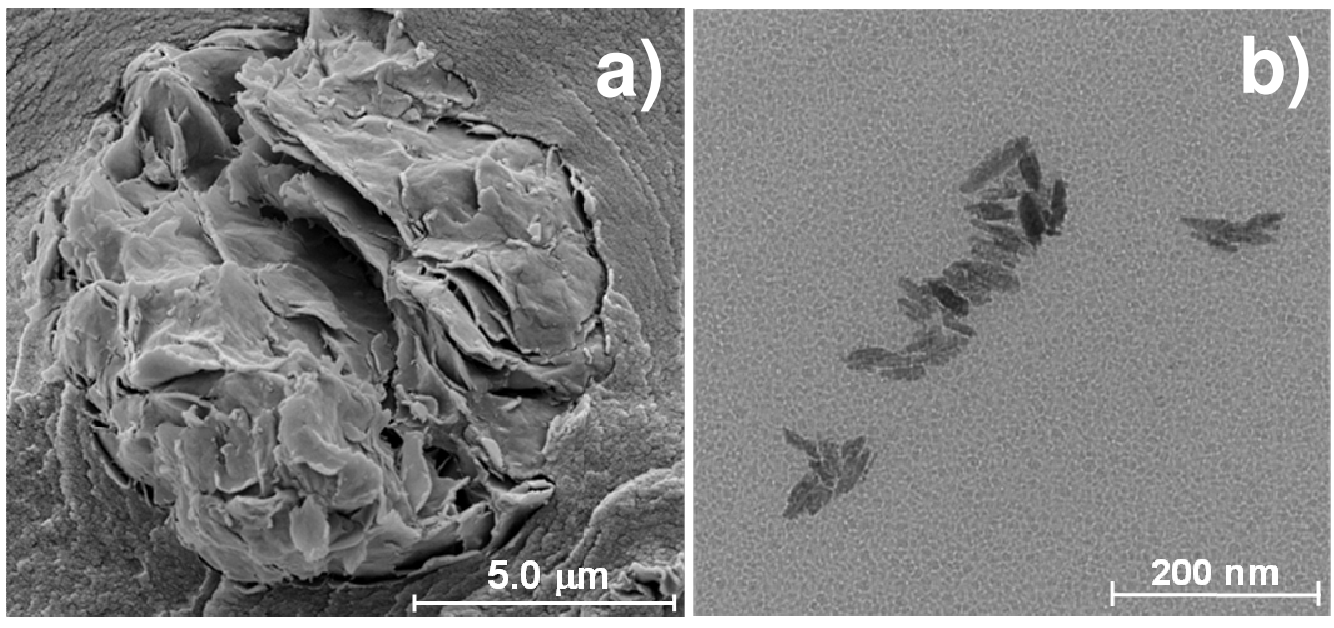

Figure 2. SEM image of a tactoid (a) and TEM image of fragments (b) arising from the sonication of a 3.0 wt.\% water dispersion of $\mathrm{Na}^{+}-\mathrm{MMT}$ after 45 minutes of sonication, according to the instrumental setup described in the main text. 


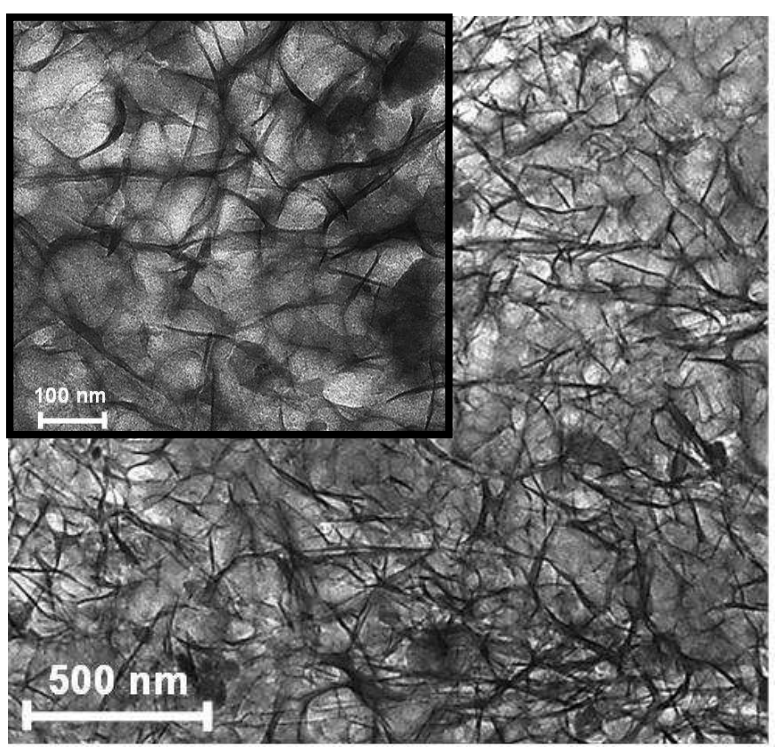

Figure 3. TEM micrographs at two different magnifications of a $3.0 \mathrm{wt} \% \mathrm{Na}^{+}-\mathrm{MMT}$ water dispersion after ultrasonic treatment according to the optimized procedure ( $15 \mathrm{~min}, 0.5$ cycles, and $50 \%$ amplitude). 

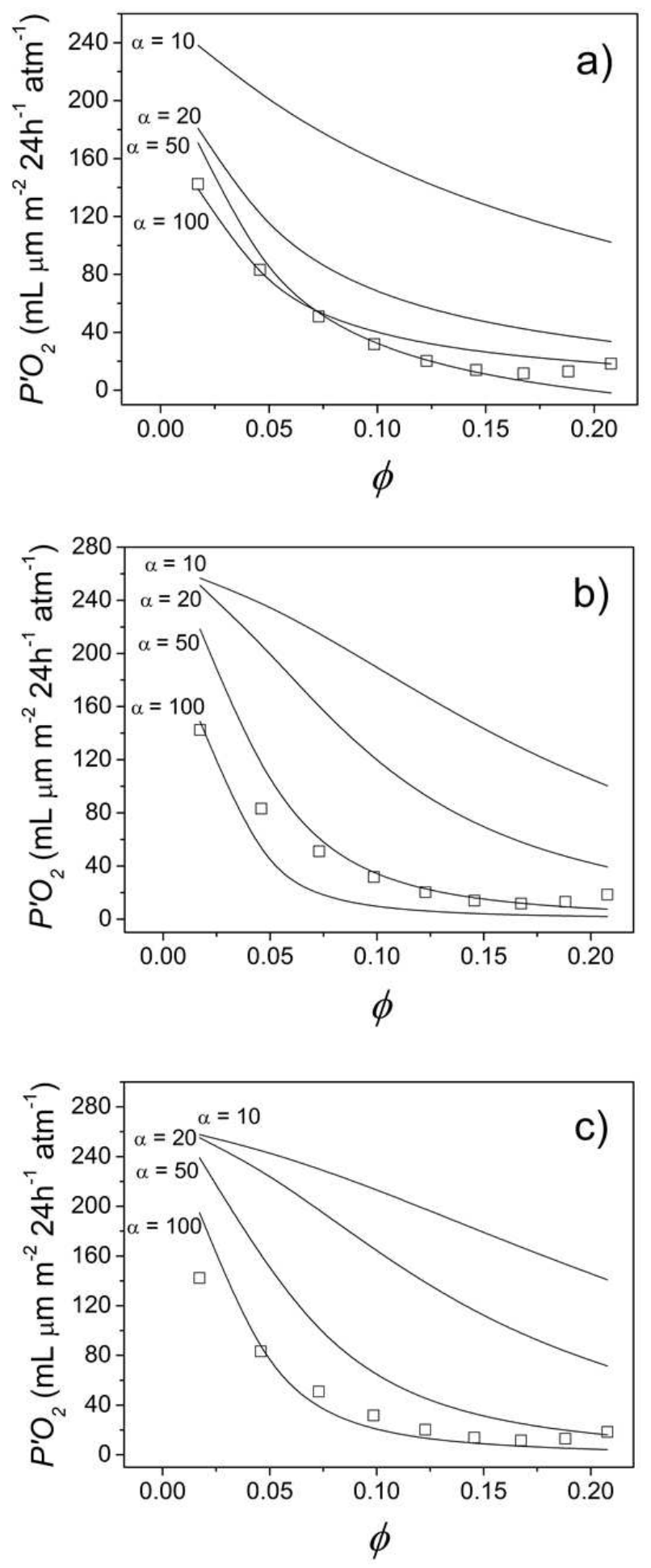

Figure 4. Oxygen permeability of the bionanocomposite coatings. Experimental "softwaregenerated" values ( $\square$ ) and values predicted by Nielsen's (a) and Cussler's (b and c) models (equation 7 and equations $8 \mathrm{a}$ and $8 \mathrm{~b}$ in the text, respectively) for different aspect ratios $(\alpha)$. 


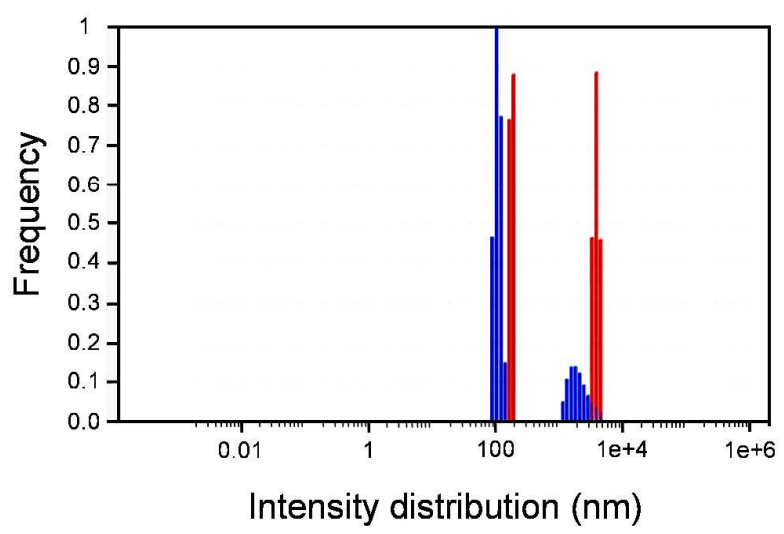

Figure 5. Particle size distribution of the $\mathrm{Na}^{+}-\mathrm{MMT}$ before (-) and after (-) sonication according to the optimized formulation (see text). 

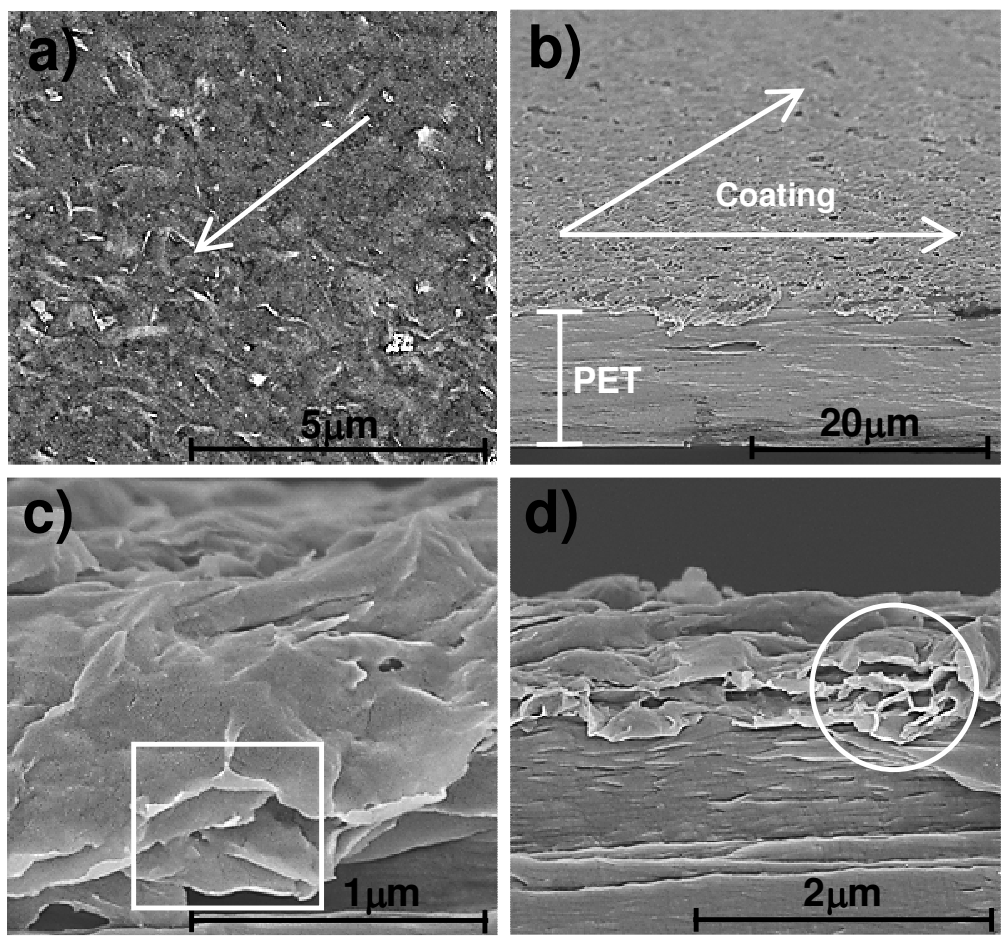

Figure 6. FE-SEM micrographs of the optimized pullulan nanocomposite coating: surface image of the coating at $5 \mathrm{k} \times$ magnification, with the arrow pointing an area of apparently randomly distributed platelets (a); cross-sectional overview at $2 \mathrm{k} \times$ magnification of the coating on top of the PET substrate, with the direction of the orientation indicated by the arrows (b); exfoliated platelets "wrapped" by pullulan at 50k $\times$ magnification, with four stacked layers within the frame (c); celllike morphology at $25 \mathrm{k} \times$ magnification, highlighted by the circle $(\mathrm{d})$. 

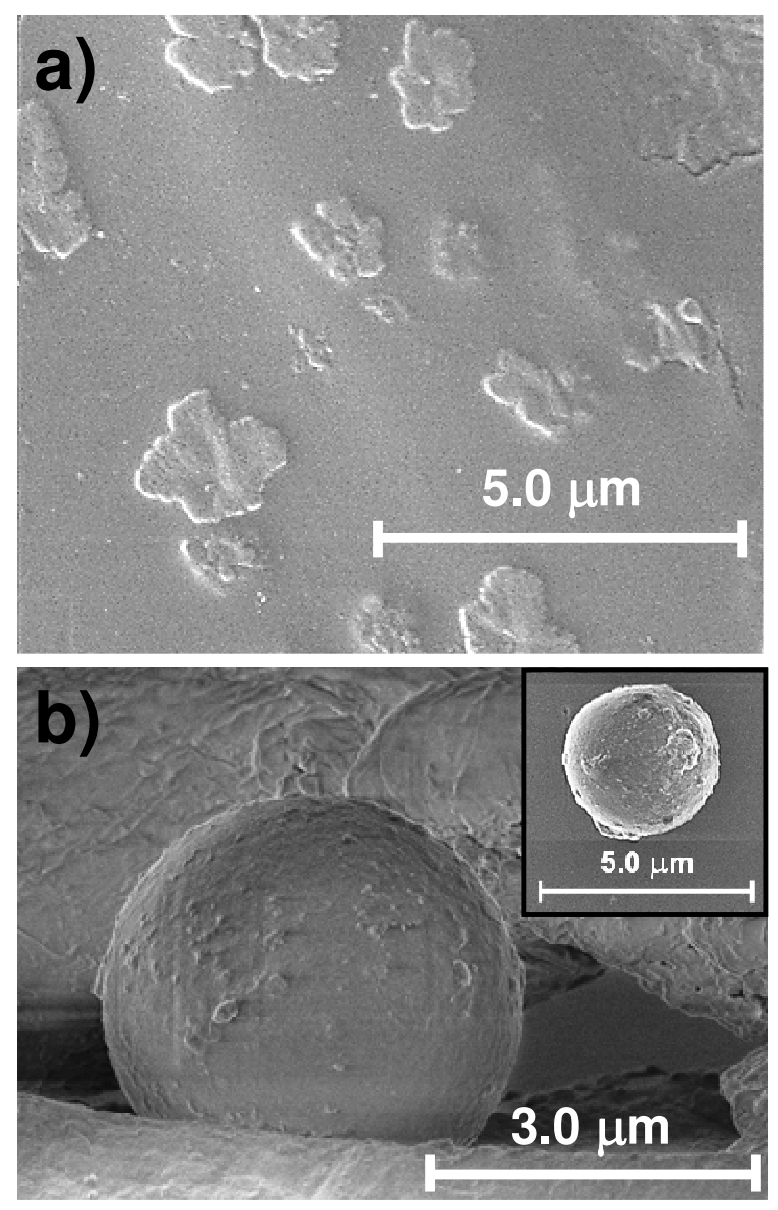

Figure 7. SEM micrographs of spherulitic formations on the pure pullulan coating surfaces: featherlike dendritic crystals at $10 \mathrm{k} \times$ magnification (a) and perfectly spherical self-associations at $15 \mathrm{k} \times$ magnification (b). The top view is shown in the inset. 
1

2

3

4

5

6

7

8

9

10

11

12

13

14

15

16

17

18

19

20

21

22

23

24

25

26

27

28

29

30

31

32

33

34

35

36

37

38

39

40

41

42

43

44

45

46

47

48

49

50

51

52

53

54

55

56

57

58

59

60
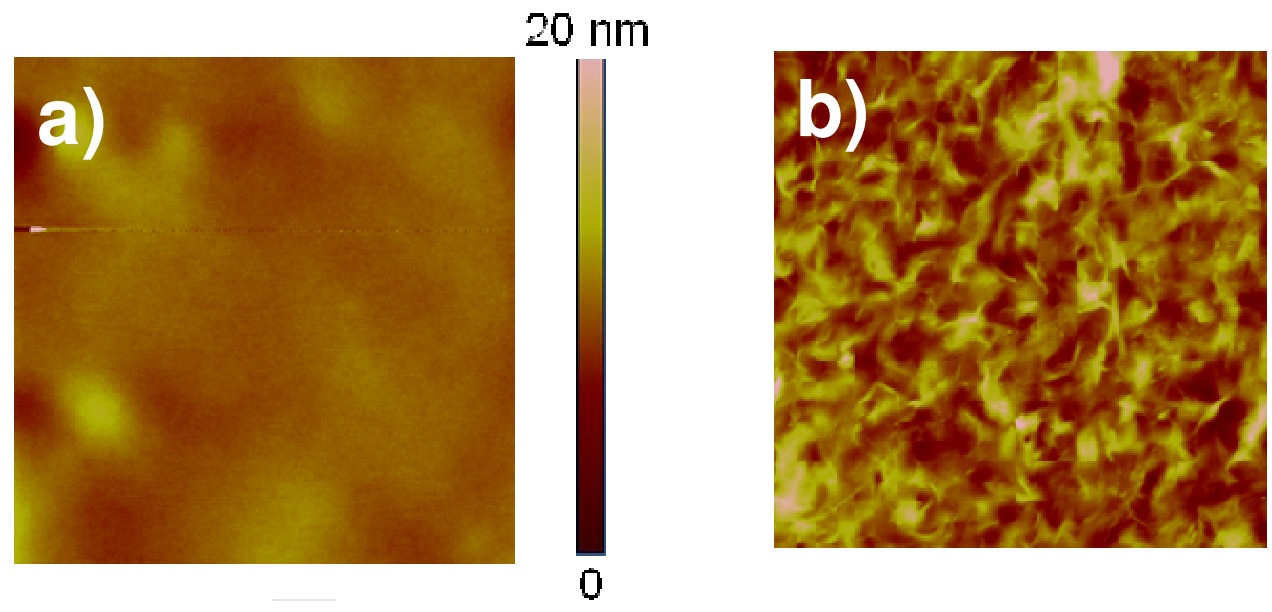

$120 \mathrm{~nm}$
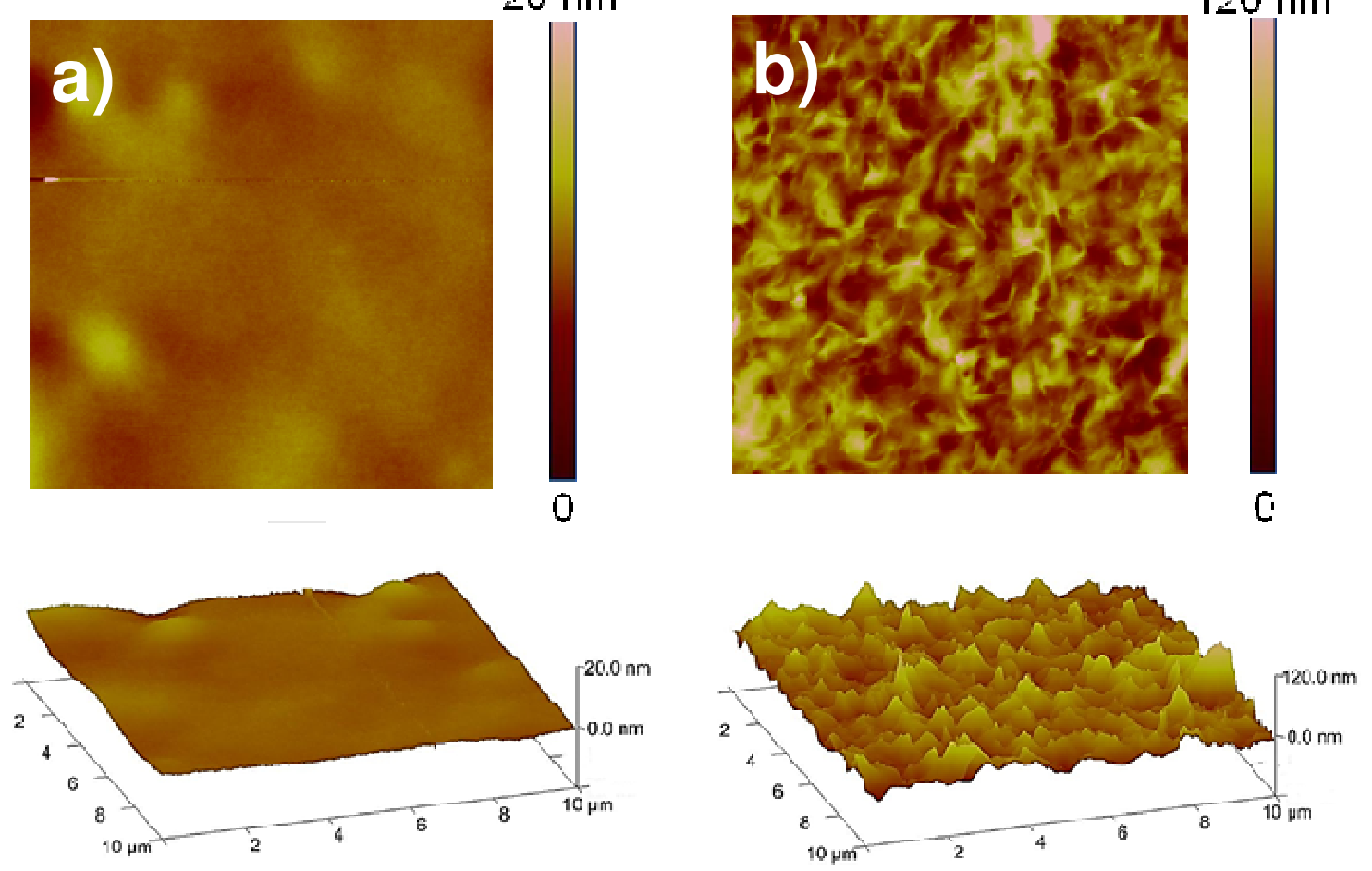

Figure 8. AFM height (upper) and 3D (lower) images $\left(10 \times 10 \mu \mathrm{m}^{2}\right)$ of pure pullulan coatings (a) and pullulan nanocomposite coatings according to the optimized formulation (b). 


\section{Tables}

Table 1. Worksheet of the CCF factorial design.

\begin{tabular}{cccccc}
\hline & & \multicolumn{2}{c}{ Variable levels } & \multicolumn{2}{c}{ Responses } \\
\cline { 3 - 6 } Exp. N & Run order & $\mathrm{X}_{1}\left(\mathrm{x}_{1}\right)^{a}$ & $\mathrm{X}_{2}\left(\mathrm{x}_{2}\right)^{b}$ & $\mathrm{Y}_{1}{ }^{c}$ & $\mathrm{Y}_{2}{ }^{d}$ \\
\hline 1 & 11 & $0.05(-1)$ & $15(-1)$ & 887.44 & 1.89 \\
2 & 8 & $0.75(+1)$ & $15(-1)$ & 196.10 & 4.25 \\
3 & 9 & $0.05(-1)$ & $45(+1)$ & 913.61 & 1.80 \\
4 & 4 & $0.75(+1)$ & $45(+1)$ & 249.94 & 4.16 \\
5 & 10 & $0.05(-1)$ & $30(0)$ & 950.66 & 1.87 \\
6 & 3 & $0.75(+1)$ & $30(0)$ & 181.688 & 4.48 \\
7 & 6 & $0.4(0)$ & $15(-1)$ & 236.99 & 3.15 \\
8 & 7 & $0.4(0)$ & $45(+1)$ & 239.42 & 2.80 \\
9 & 5 & $0.4(0)$ & $30(0)$ & 297.60 & 3.12 \\
10 & 2 & $0.4(0)$ & $30(0)$ & 307.27 & 2.72 \\
11 & 1 & $0.4(0)$ & $30(0)$ & 309.82 & 2.88 \\
\hline
\end{tabular}

${ }^{a}$ Inorganic/organic ratio (I/O). ${ }^{b}$ Ultrasonication time (min). ${ }^{c}$ Oxygen permeability coefficient $\left(P^{\prime} \mathrm{O}_{2}, \mathrm{~mL} \mu \mathrm{m} \mathrm{m}^{-2} 24 \mathrm{~h}^{-1} \mathrm{~atm}^{-1}\right) .{ }^{d}$ Haze $(\%)$. Coded values are reported between brackets. 
Table 2. Regression coefficients and level of significance for the fitted model.

\begin{tabular}{|c|c|c|c|c|c|c|}
\hline \multirow[b]{2}{*}{ Factor } & \multicolumn{3}{|c|}{$P^{\prime} O_{2}$} & \multicolumn{3}{|c|}{ Haze } \\
\hline & $\begin{array}{c}\text { effect } \\
\left(\mathrm{mL} \mu \mathrm{m} \mathrm{m}^{-2} 24 \mathrm{~h}^{-1} \mathrm{~atm}^{-1}\right)\end{array}$ & $\begin{array}{l}\text { standard } \\
\text { error }\end{array}$ & $p$-value & $\begin{array}{l}\text { effect } \\
(\%)\end{array}$ & $\begin{array}{l}\text { standard } \\
\text { error }\end{array}$ & $p$-value \\
\hline$b_{0}$ & 23.2714 & 0.5400 & $0.0000 *$ & 2.92 & 0.0783 & $0.0000 *$ \\
\hline$b_{1}$ & -25.9216 & 0.4773 & $0.0000^{*}$ & 1.1700 & 0.0692 & $0.0000 *$ \\
\hline$b_{2}$ & 1.0568 & 0.4124 & 0.0505 & -0.0883 & 0.0598 & 0.1998 \\
\hline$b_{1} b_{1}$ & 24.4807 & 0.7207 & $0.0000 *$ & -0.0800 & 0.1045 & 0.4786 \\
\hline$b_{2} b_{2}$ & -4.6751 & 0.7394 & $0.0015^{*}$ & 0.0350 & 0.1072 & 0.7574 \\
\hline
\end{tabular}

*Significant factors $(p<0.05$ or $95 \%$ confidence interval). 
Table 3. Analysis of Variance (ANOVA) table for the $P^{\prime} O_{2}$ responses and haze.

\begin{tabular}{|c|c|c|c|c|c|c|c|c|c|c|}
\hline & \multicolumn{5}{|c|}{$\mathrm{Y}_{1}$ (permeability coefficient) } & \multicolumn{5}{|c|}{$\mathrm{Y}_{2}$ (haze) } \\
\hline $\begin{array}{l}\text { Source of } \\
\text { variation }\end{array}$ & $D F^{a}$ & $S S^{b}$ & $M S^{c}$ & $F^{d}$ & $p^{e}$ & $D F^{a}$ & $S S^{b}$ & $M S^{c}$ & $F^{d}$ & $p^{e}$ \\
\hline Total & 10 & 17866.2 & 1786.6 & & & 10 & 88.866 & 8.8866 & & \\
\hline Constant & 1 & 12460.1 & 12460.1 & & & 1 & 82.024 & 82.024 & & \\
\hline Total corrected & 9 & 5406.0 & 600.6 & & & 9 & 6.8418 & 0.7602 & & \\
\hline Regression & 4 & 5400.9 & 1350.2 & 1323.0 & 0.000 & 4 & 6.7345 & 1.6836 & 78.43 & 0.000 \\
\hline Residual & 5 & 5.1028 & 1.0205 & & & 5 & 0.1073 & 0.0214 & & \\
\hline $\begin{array}{l}\text { Lack of fit } \\
\text { (Model error) }\end{array}$ & 3 & 4.6109 & 1.537 & 6.2498 & 0.141 & 3 & 0.0262 & 0.0087 & 0.2160 & 0.879 \\
\hline \multirow{2}{*}{$\begin{array}{l}\text { Pure error } \\
\text { (Replicate error) }\end{array}$} & 2 & 0.4918 & 0.2459 & & & 2 & 0.0810 & 0.0405 & & \\
\hline & \multicolumn{5}{|c|}{$\begin{array}{l}R^{2}=0.999 \\
K^{2}=0.994\end{array}$} & \multicolumn{5}{|c|}{$\begin{array}{l}R^{2}=0.984 \\
K^{2}=0.955\end{array}$} \\
\hline
\end{tabular}

${ }^{a}$ Degrees of freedom. ${ }^{b}$ Sum of squares. ${ }^{c}$ Mean square. ${ }^{d} F$ ratio, the model significance (regression/residual). ${ }^{e} p$-value. 
Table 4. Volume fraction of the filler, oxygen permeability coefficient $\left(P^{\prime} O_{2}\right)$ of the coated PET and of the bionanocomposite coatings.

\begin{tabular}{ccc}
\hline $\begin{array}{c}\text { Filler volume } \\
\text { fraction }^{a}\end{array}$ & $\begin{array}{c}P^{\prime} \mathrm{O}_{2}(\text { total })^{b} \\
\left(\mathrm{~mL} \mu \mathrm{m} \mathrm{m}^{-2} 24 \mathrm{~h}^{-1} \mathrm{~atm}^{-1}\right)\end{array}$ & $\begin{array}{c}P^{\prime} \mathrm{O}_{2}(\text { coating })^{c} \\
\left(\mathrm{~mL} \mu \mathrm{m} \mathrm{m}^{-2} 24 \mathrm{~h}^{-1} \mathrm{~atm}^{-1}\right)\end{array}$ \\
\hline 0.017 & 883.24 & 142.32 \\
0.046 & 659.76 & 83.25 \\
0.073 & 476.06 & 50.98 \\
0.098 & 332.15 & 31.79 \\
0.123 & 228.01 & 20.27 \\
0.145 & 163.66 & 13.93 \\
0.167 & 139.08 & 11.65 \\
0.188 & 154.29 & 13.06 \\
0.207 & 209.28 & 18.37
\end{tabular}

${ }^{a}$ Calculated for a given filler density $\rho_{\text {clays }}=2.86 \mathrm{~g} \mathrm{~cm}^{-3} \cdot{ }^{b}$ Data extrapolated from the software, according to the model developed with reference to Eq. 3 in the text. ${ }^{c}$ According to Eq. 6 in the text and considering $P^{\prime} O_{2 \text { PET }}\left(70 \% \mathrm{RH}\right.$ and $\left.23^{\circ} \mathrm{C}\right) \sim 1560 \mathrm{~mL} \mu \mathrm{m} \mathrm{m}^{-2} 24 \mathrm{~h}^{-1} \mathrm{~atm}^{-1}$. 


\section{Table of Contents}

3

4

5

6

7

8

9

10

11

12

13

14

15

16

17

18

19

20

21

22

23

24

25

26

27

28

29

30

31

32

33

34

35

36

37

38

39

40

41

42

43

44

45

46

47

48

49

50

51

52

53

54

55

56

57

58

59

60
36

ACS Paragon Plus Environment 